\title{
Obsessive-Compulsive Personality Disorder
}

National Cancer Institute

\section{Source}

National Cancer Institute. Obsessive-Compulsive Personality Disorder. NCI Thesaurus.

Code $C 92638$.

A disorder characterized by an enduring pattern of inflexibility, extreme orderliness, and perfectionism which interfere with efficiency and which may manifest in many different contexts, including work and leisure activities, financial matters, and issues of morality or ethics. 